\title{
STABILITY-INDICATING METHOD DEVELOPMENT AND VALIDATION FOR THE ESTIMATION OF CABOZANTINIB IN PHARMACEUTICAL DOSAGE FORMS BY ULTRA-PERFORMANCE LIQUID CHROMATOGRAPHY
}

\author{
GORJA ASHOK ${ }^{1 *}$, SUMANTA MONDAL ${ }^{2}$ \\ ${ }^{1}$ Department of Pharmaceutical Analysis and QA, Faculty of Pharmacy, Gland Institute of Pharmaceutical Sciences, Kothapet, Medak, \\ Telangana, India. ${ }^{2}$ Department of Pharmaceutical Chemistry, Faculty of Pharmacy, GITAM Institute of Pharmacy GITAM University, \\ Rushikonda, Visakhapatnam, Andhra Pradesh, India. Email: ashokgorja8@gmail.com
}

Received: 19 May 2018, Revised and Accepted: 15 June 2018

\section{ABSTRACT}

Objective: The proposed study aimed to develop a stability-indicating ultra-performance liquid chromatography (UPLC) method for the estimation of cabozantinib in pharmaceutical dosage form and validate the method in accordance with the International Conference on Harmonization guidelines.

Methods: The optimized conditions for the developed UPLC method are Acquity UPLC Hibar C18 $(100 \mathrm{~mm} \times 2.1 \mathrm{~mm}, 1.7 \mu)$ column maintained at $30^{\circ} \mathrm{C}$ with mobile phase consisting of $0.1 \%$ orthophosphoric acid and acetonitrile in the ratio of $55: 45 \% \mathrm{v} / \mathrm{v}$ on isocratic mode at flow rate of $0.3 \mathrm{~mL} /$ min. The sample was detected at $244 \mathrm{~nm}$.

Results: The retention time for cabozantinib was deemed $1.3 \mathrm{~min}$. The developed method was validated for accuracy, precision, specificity, ruggedness, robustness, and solution stability. The method obeyed Beer's law in the concentration range of $20 \mu \mathrm{g} / \mathrm{mL}$ and $120 \mu \mathrm{g} / \mathrm{mL}$ with correlation coefficient of 0.9997. Forced degradation studies were conducted by exposing the drug solution to numerous stress conditions such as acidic, basic, peroxide, neutral, photolytic, and thermal conditions. The net degradation was considered within the limits, indicating that drug is stable in stressed conditions.

Conclusion: The developed method for the estimation of cabozantinib can be utilized for the routine analysis of pharmaceutical dosage form.

Keywords: Cabozantinib, Stability indicating, Method development, Validation, Ultra-performance liquid chromatography.

(c) 2018 The Authors. Published by Innovare Academic Sciences Pvt Ltd. This is an open access article under the CC BY license (http://creativecommons. org/licenses/by/4. 0/) DOI: http://dx.doi.org/10.22159/ajpcr.2018.v11i9.27409

\section{INTRODUCTION}

Cabozantinib (Fig. 1) [1-5] chemically defined as $\mathrm{N}-(4-(6,7-$ dimethoxyquinolin-4-yloxy)phenyl)-N'-(4-fluorophenyl)cyclopropane1,1-dicarboxamide, (2S)-hydroxybutanedioate. It is white to off-white solid, practically insoluble in aqueous media. It has pKa values of 5.9 and 13.46. It belongs to anticancer category which acts by inhibiting tyrosine kinase activity of receptors that participate in pathologic processes such as oncogenesis, metastasis, tumor angiogenesis, and maintenance of tumor microenvironment. It is used in the treatment of medullary thyroid cancer and a second-line treatment for renal cell carcinoma.

Ultra-performance liquid chromatography (UPLC) [6] is specially designed to withstand higher system pressure during chromatographic analysis so that it enables a significant decrease in separation time and solvent consumption. UPLC columns packed with $1.7 \mu \mathrm{m}$ sized particles provide not only increased efficiency but also the ability to work at an increased linear velocity without loss of efficiency, providing both resolution and speed. Using advantages of UPLC, a number of applications in different fields including pharmacy, clinical analysis, and pesticide analysis have been recorded.

The literature survey reveals that there are only few methods developed for the estimation of cabozantinib using LC coupled with tandem mass spectrometry method (LC-MS/MS) [7,8], spectrofluorimetric method [9] and UPLC coupled with tandem mass spectrometry method (UPLC-MS/MS)[10].

As there was no method developed using UPLC, the present study aimed to develop and validate a UPLC stability-indicating method for the estimation of cabozantinib in pharmaceutical dosage form.

\section{METHODS}

Reagents and chemicals

Cabozantinib working standard was procured from Spectrum Labs, Hyderabad, as a gift sample. The Cometriq capsules were purchased from a local pharmacy. All the chemicals used were of AR grade purchased from Merck, Mumbai. All the solvents used were of high-performance LC grade purchased from Sigma-Aldrich, Mumbai.

\section{Chromatographic conditions and instruments}

The ACQUITY UPLC [11] system equipped with binary solvent manager, sample manager, ultraviolet (UV) detector, and Hibar C18 (100 mm $\times$ $2.1 \mathrm{~mm}, 1.7 \mu$ ) column was used for the determination of cabozantinib. The optimized conditions included $0.1 \%$ orthophosphoric acid and acetonitrile $(55: 45 \% \mathrm{v} / \mathrm{v})$ as mobile phase run on an isocratic mode at a flow rate of $0.3 \mathrm{~mL} / \mathrm{min}$. The column was held at $30^{\circ} \mathrm{C}$ and detection was done at $244 \mathrm{~nm}$. Further, equipment included $\mathrm{pH}$ meter, ultrasonic bath sonicator, and weighing balance.

\section{Preparation of mobile phase}

Mixture of $0.1 \%$ orthophosphoric acid and acetonitrile in the ratio of $55: 45 \% \mathrm{v} / \mathrm{v}$ was used as mobile phase

\section{Preparation of standard and sample solutions}

About $80 \mathrm{mg}$ of cabozantinib working standard was dissolved in $100 \mathrm{~mL}$ of diluent. Then, $1 \mathrm{~mL}$ of the above stock solution was diluted to $10 \mathrm{~mL}$ using diluent to get a concentration of $80 \mu \mathrm{g} / \mathrm{mL}$.

20 capsules (Cometriq) were weighed accurately and average weight was calculated. An amount equivalent to $80 \mathrm{mg}$ of the drug was 
dissolved in $100 \mathrm{~mL}$ of diluent, filtered the solution, and diluted $1 \mathrm{~mL}$ of the above solution to $10 \mathrm{~mL}$ with diluent.

\section{Method validation}

The developed method was validated in accordance with the International Conference on Harmonization (ICH) guidelines [12,13].

\section{Specificity}

The specificity of the method was determined by comparing the drug solution to the placebo solution and observed for the interference of placebo peak with drug peak.

\section{Accuracy}

Accuracy of the method was determined in accordance with percentage recovery. The drug solution along with sample was prepared in three concentration levels, i.e. $50 \%, 100 \%$, and $150 \%$. Then, the percentage recovery was calculated.

\section{Precision}

Precision of the method was established by injecting the standard solution 6 times into the UPLC system and percentage relative standard deviation (RSD) was calculated.

\section{Linearity}

Linearity of the method was determined by preparing a series of dilutions ranging from $20 \mu \mathrm{g} / \mathrm{mL}$ to $120 \mu \mathrm{g} / \mathrm{mL}$ and injecting them into UPLC system.

\section{Ruggedness}

Ruggedness was determined by injecting the standard solution into UPLC 6 times for different days. The percentage RSD was calculated.

\section{Robustness}

Robustness of the method was determined by varying the optimized analytical conditions such as mobile phase composition by $\pm 5 \%$, flow rate by $\pm 0.1 \mathrm{~mL} / \mathrm{min}$, and column oven temperature by $\pm 5^{\circ} \mathrm{C}$.

\section{Solution stability}

Solution stability determined on the basis of analyzing the standard drug solution after storage for $24 \mathrm{~h}$ under laboratory conditions.

\section{Forced degradation studies}

Forced degradation studies $[14,15]$ were carried out for drug by exposing the drug solution to the various stress conditions such as acidic $\left(2 \mathrm{~N}\right.$ hydrochloric acid for $30 \mathrm{~min}$ at $60^{\circ} \mathrm{C}$ ), basic $(2 \mathrm{~N}$ sodium hydroxide for $30 \mathrm{~min}$ at $\left.60^{\circ} \mathrm{C}\right)$, peroxide $\left(20 \%\right.$ hydrogen peroxide $\left[\mathrm{H}_{2} \mathrm{O}_{2}\right]$ for $30 \mathrm{~min}$ at $60^{\circ} \mathrm{C}$ ), neutral (refluxing the drug in water for $6 \mathrm{~h}$ at $60^{\circ} \mathrm{C}$ ), photolytic $\left(105^{\circ} \mathrm{C}\right.$ for $6 \mathrm{~h}$ ), and thermal (exposing the drug solution to UV light by keeping the beaker in UV chamber for 7 day or $200 \mathrm{Wt} \mathrm{h} / \mathrm{m}^{2}$ in photostability chamber) conditions.

\section{RESULTS}

From the UV spectrum, detection wavelength for Cabozantinib was found to be $244 \mathrm{~nm}$.

\section{DISCUSSION}

For the development of a method for the estimation of cabozantinib in pharmaceutical dosage form, initially, many mobile phases and many columns were tried to elute the drug peak with less tailing factor and more plate count. Acquity UPLC Hibar C18 $(100 \mathrm{~mm} \times 2.1 \mathrm{~mm}, 1.7 \mu)$ column and $0.1 \%$ OPA:acetonitrile $(55: 45 \% \mathrm{v} / \mathrm{v})$ as mobile phase were selected based on peak parameters. The detection wavelength was found to be $244 \mathrm{~nm}$ as shown in Fig. 2 of the UV spectrum.

Prepared standard solution, sample solution, and the blank solution were injected into the UPLC system, and system suitability parameters were noted as summarized in Table 1 along with chromatograms as showed in Fig. 3a-c, respectively.

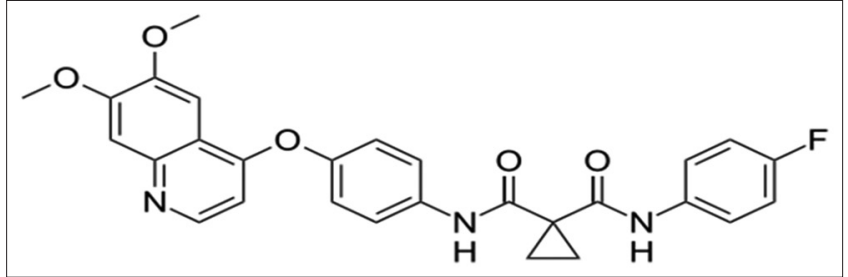

Fig. 1: Chemical structure of cabozantinib

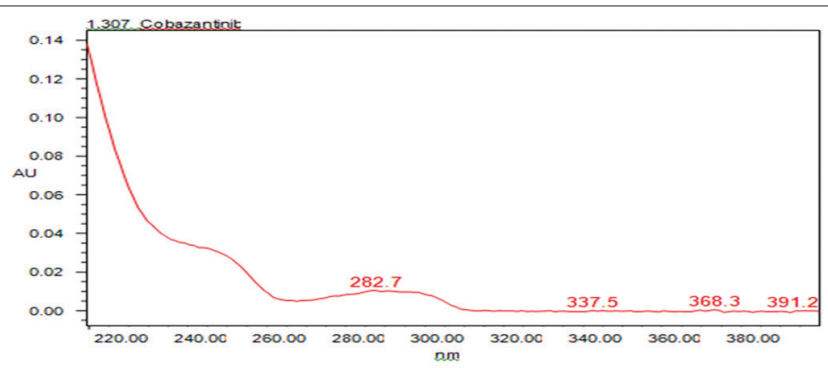

Fig. 2: Ultraviolet spectrum of cabozantinib

Table 1: System suitability and validation parameter results

\begin{tabular}{lll}
\hline Parameter & Result & Result \\
\hline Precision (\%RSD, n) & 0.3 & \\
Accuracy (\% recovery, n) & $99.57-99.91 \%$ & \\
Specificity & Specific, no & \\
& interference & \\
Linearity range $(\mu \mathrm{g} / \mathrm{mL})$ & $20-120$ & \\
Correlation coefficient, $\mathrm{r}$ & 0.9997 & \\
Limit of detection $(\mu \mathrm{g} / \mathrm{mL})$ & 0.15 & \\
Limit of quantitation $(\mu \mathrm{g} / \mathrm{mL})$ & 0.47 & Day 2 \\
Ruggedness (\%RSD, n) & Day 1 & 0.3 \\
& 0.5 & More flow rate \\
Robustness (\%RSD, $\mathrm{n})$ & Less flow rate & 0.5 \\
& 0.4 & More mobile \\
& Less mobile & phase (organic) \\
& 1.0 & 0.4 \\
& Less column & More column \\
& temperature & temperature \\
& 0.7 & 0.3 \\
Solution stability (\%RSD, n) & & \\
USP plate count & & \\
USP tailing factor & & \\
Day 1 (0 h) & Day 2 (after & \\
& 24 h) & \\
0.5 & 0.3 & \\
& 2943 & \\
& 1.28 & \\
\hline
\end{tabular}

n: Number of samples, i.e., 6 samples, \%RSD: \% Relative standard deviation

The developed method was identified to obey Beer's law in the concentration range of $20 \mu \mathrm{g} / \mathrm{mL}-120 \mu \mathrm{g} / \mathrm{mL}$ with correlation coefficient of 0.9997 . A linearity graph was plotted between concentration and peak area as showed in Fig. 4 and results as presented in Table 1.

The method was found to be accurate as the percentage recovery was 99.57-99.91\% and was within the limits. The percentage RSD was determined to be 0.3 , which indicates that the method was precise. The method was shown to be specific, as there is no interference of retention time of placebo peak with that of drug peak. The placebo chromatogram was displayed in Fig. 5.

Forced degradation studies results indicate that the drug was reported to be stable in various stress conditions as net degradation was found to 


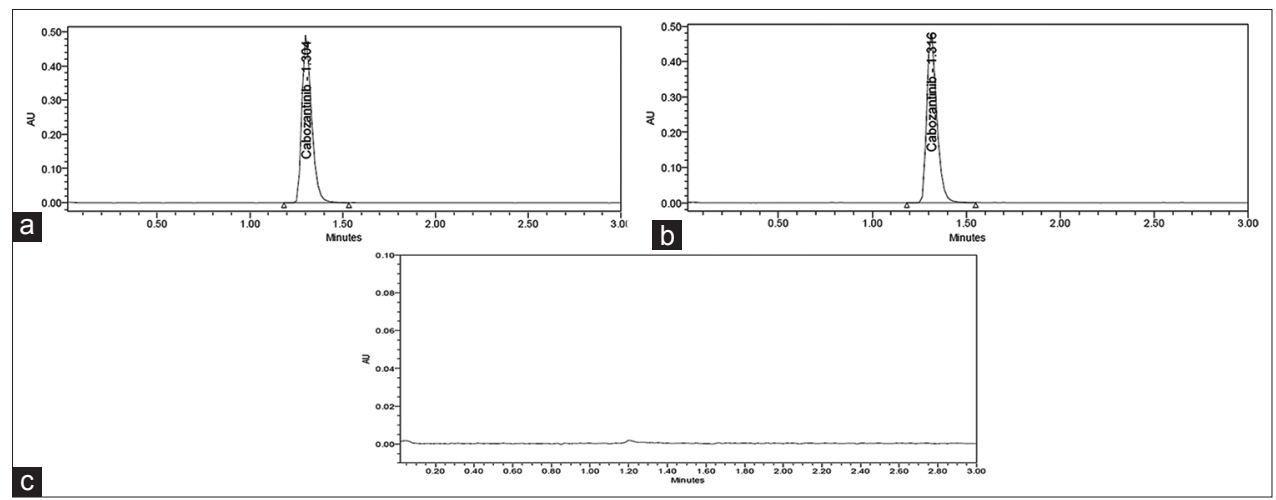

Fig. 3: (a) Ultra-performance liquid chromatography (UPLC) chromatogram of a standard solution, (b) UPLC chromatogram of sample solution, (c) UPLC chromatogram of blank solution

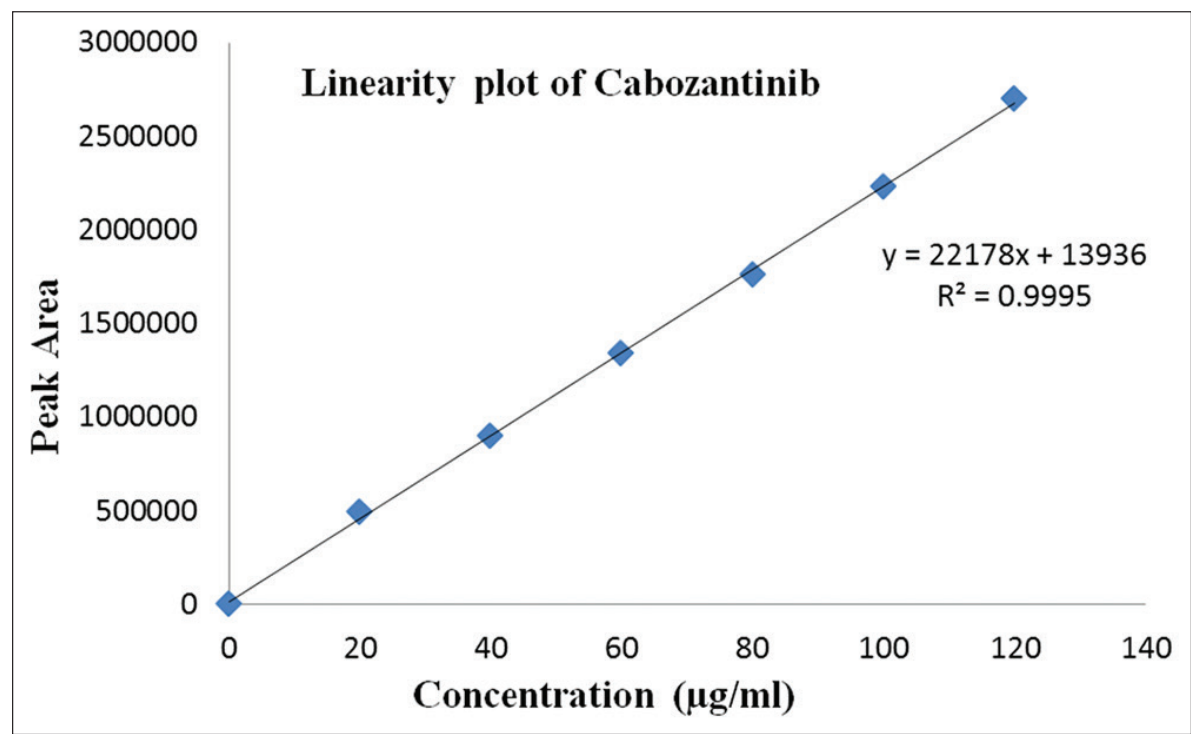

Fig. 4: Linearity plot of cabozantinib

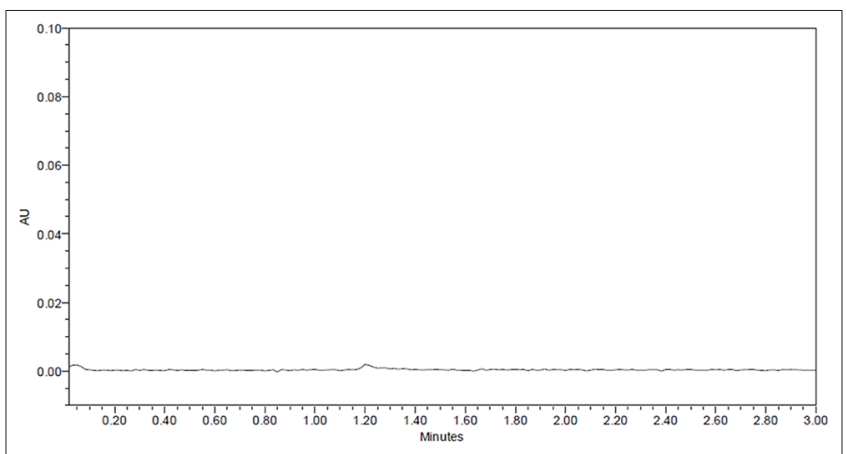

Fig. 5: Ultra-performance liquid chromatography chromatogram of placebo solution

be within the limits. The chromatograms were illustrated in Fig. 6 and results were outlined in Table 2 .

\section{CONCLUSION}

A specific, accurate, and precise stability-indicating method was developed for the estimation of cabozantinib in pharmaceutical dosage form using UPLC. The method was validated using numerous validation parameters, and the method was found to be linear, precise, accurate, specific, and robust. From the degradation studies conducted, it infers
Table 2: Forced degradation studies results

\begin{tabular}{llll}
\hline $\begin{array}{l}\text { Stress } \\
\text { condition }\end{array}$ & $\%$ assay & $\begin{array}{l}\text { \% area of } \\
\text { degradation peak }\end{array}$ & \% degradation \\
\hline $\begin{array}{l}2 \mathrm{~N} \mathrm{HCl} \text { for } \\
30 \mathrm{~min} \text { at } 60^{\circ} \mathrm{C}\end{array}$ & 97.69 & 0.08 & 2.31 \\
$2 \mathrm{~N} \mathrm{NaOH} \mathrm{for}$ & 96.87 & 0.02 & 3.13 \\
$\begin{array}{l}30 \mathrm{~min} \text { at } 60^{\circ} \mathrm{C} \\
20 \% \mathrm{H}_{2} \mathrm{O}_{2} \text { for }\end{array}$ & 98.26 & - & 1.74 \\
$30 \mathrm{~min}$ at $60^{\circ} \mathrm{C}$ & & - & 0.55 \\
$\begin{array}{l}\text { Water for } 6 \mathrm{~h} \\
\text { at } 60^{\circ} \mathrm{C}\end{array}$ & 99.45 & - & 0.95 \\
$\mathrm{UV}$ light 200 & 99.05 & - & 1.30 \\
$\begin{array}{l}\text { Wts/h or } 7 \text { day } \\
105^{\circ} \mathrm{C} \text { for } 6 \mathrm{~h}\end{array}$ & 98.70 & - & \\
\hline
\end{tabular}

that cabozantinib was more stable at more concentrations of acid, base, peroxide, thermal, UV, and water stress study conditions. The run time was $3 \mathrm{~min}$ which enables rapid quantitation of many samples in routine and quality control analysis of capsule formulation.

\section{ACKNOWLEDGMENT}

The authors are thankful to the Spectrum Labs, Hyderabad, for providing the cabozantinib as the gift samples and also for providing required facilities to undertake this research work. 

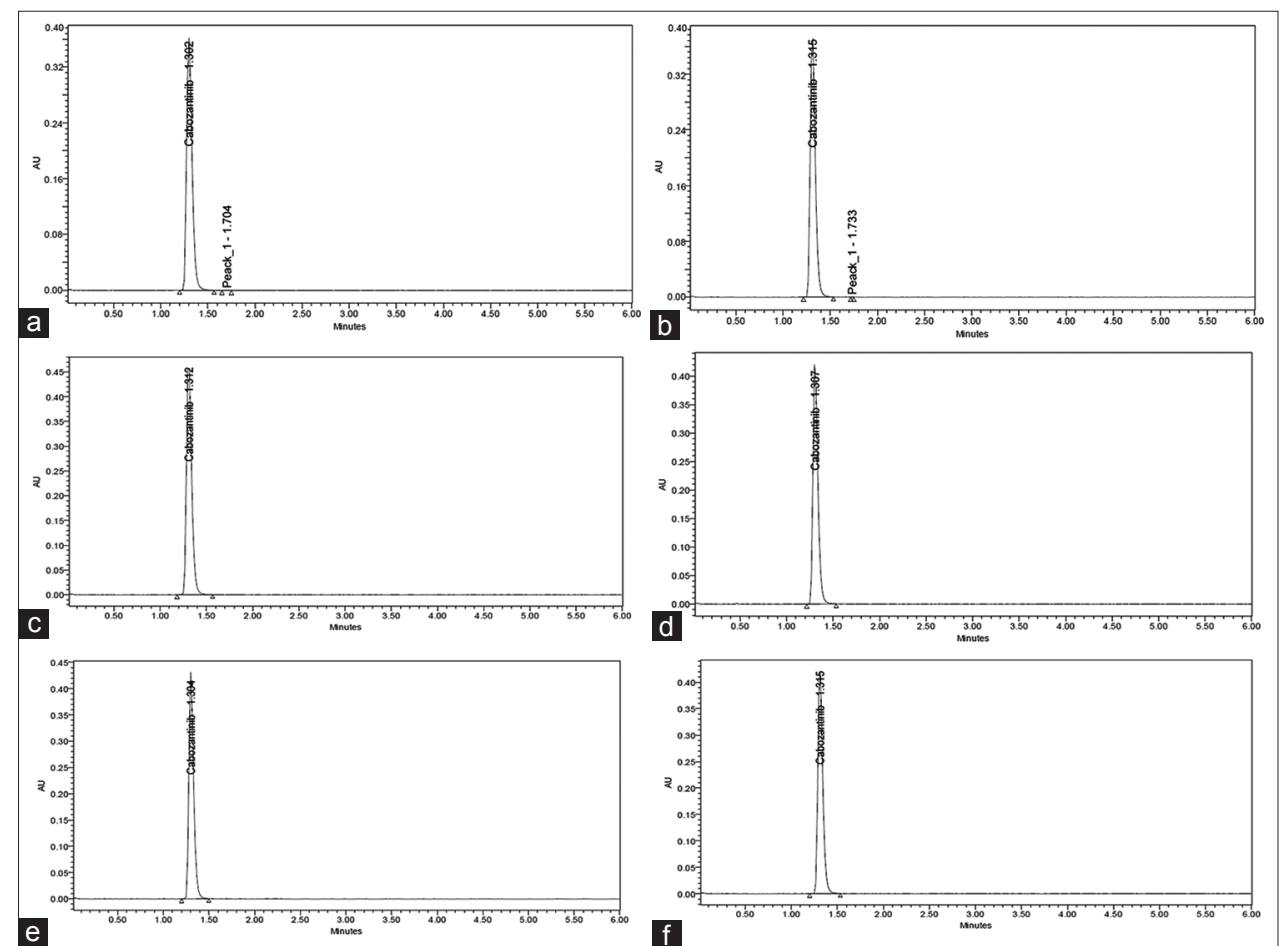

Fig. 6: (a) Acid degradation ultra-performance liquid chromatography (UPLC) chromatogram, (b) base degradation UPLC chromatogram, (c) peroxide degradation UPLC chromatogram, (d) water stress study UPLC chromatogram, (e) photostability degradation UPLC chromatogram, (f) dry heat study UPLC chromatogram

\section{AUTHOR'S CONTRIBUTIONS}

All authors contribute equally to this manuscript.

\section{CONFLICTS OF INTEREST}

The authors claim that they have no conflicts of interest. It has not meant to publish elsewhere. Moreover, it has not meant simultaneously presented for publication elsewhere. All authors have decided to the submission to the journal.

\section{REFERENCES}

1. Kurzrock R, Sherman SI, Ball DW, Forastiere AA, Cohen RB, Mehra R, et al. Activity of XL184 (Cabozantinib), an oral tyrosine kinase inhibitor, in patients with medullary thyroid cancer. J Clin Oncol 2011;29:2660-6.

2. Yakes FM, Chen J, Tan J, Yamaguchi K, Shi Y, Yu P, et al. Cabozantinib (XL184), a novel MET and VEGFR2 inhibitor, simultaneously suppresses metastasis, angiogenesis, and tumor growth. Mol Cancer Ther 2011;10:2298-308

3. Zhang J, Yang PL, Gray NS. Targeting cancer with small molecule kinase inhibitors. Nat Rev Cancer 2009;9:28-39.

4. Arora A, Scholar EM. Role of tyrosine kinase inhibitors in cancer therapy. J Pharmacol Exp Ther 2005;315:971-9.

5. Walker JG, Ahern MJ, Coleman M, Weedon H, Papangelis V, Beroukas D, et al. Changes in synovial tissue jak-STAT expression in rheumatoid arthritis in response to successful DMARD treatment. Ann Rheum Dis 2006;65:1558-64.

6. Chakravarthy VA, Sailaja BB, Kumar AP. Development and validation of a dissolution method for frovatriptan tablets by reversed phase UPLC. Int J Pharm Pharm Sci 2015;7:125-30.
7. Su Q, Li J, Ji X, Li J, Zhou T, Lu W, et al. An LC-MS/MS method for the quantitation of cabozantinib in rat plasma: Application to a pharmacokinetic study. J Chromatogr B Analyt Technol Biomed Life Sci 2015;985:119-23.

8. Kadi AA, Abdelhameed AS, Darwish HW, Attwa MW, Bakheit AH. Liquid chromatographic-tandem mass spectrometric assay for simultaneous quantitation of tofacitinib, cabozantinib and afatinib in human plasma and urine. Trop J Pharm Res 2016;15:2683-92.

9. Darwish HW, Abdelhameed AS, Bakheit AH, Alanazi AM. A new method to determine the new C-Met inhibitor "Cabozantinib" in dosage form and human plasma via micelle-enhanced spectrofluorimetry. RSC Adv 2015;51:40455-1316.

10. Wang $\mathrm{X}$, Wang $\mathrm{S}$, Lin $\mathrm{F}$, Zhang $\mathrm{Q}$, Chen $\mathrm{H}$, Wang $\mathrm{X}$, et al. Pharmacokinetics and tissue distribution model of cabozantinib in rat determined by UPLC-MS/MS. J Chromatogr B Analyt Technol Biomed Life Sci 2015;983-984:125-31.

11. Mule KL. Rapid analytical method for assay determination for prochlorperazine edisylate drug substances by ultra-performance liquid chromatography. Int J Curr Pharm Res 2017;9:118-22.

12. ICH: Q2 (R1). Validation of Analytical Procedures: Text and Methodology. Geneva: ICH: Q2 (R1); 2005.

13. ICH, Q2B. Harmonized Tripartite Guideline, Validation of Analytical Procedure: Methodology, IFPMA. In: Proceedings of the International Conference on Harmonization, Geneva; 1996.

14. Ngwa G. Forced degradation studies as an integral part of HPLC stability indicating method development. Drug Delivery Technol 2010;10:56-9.

15. Swetha A, Kuber BR. A novel stability-indicating reverse phase liquid chromatographic method for the simultaneous estimation of metformin and teneligliptin in pure and pharmaceutical formulations. Int J Pharm Pharm Sci 2017;9:163-9. 